Prof. Dr. Burcu KAYA ERDEM / Yapay Zekânın Medya ve Yayıncılık Alanına Etkisi

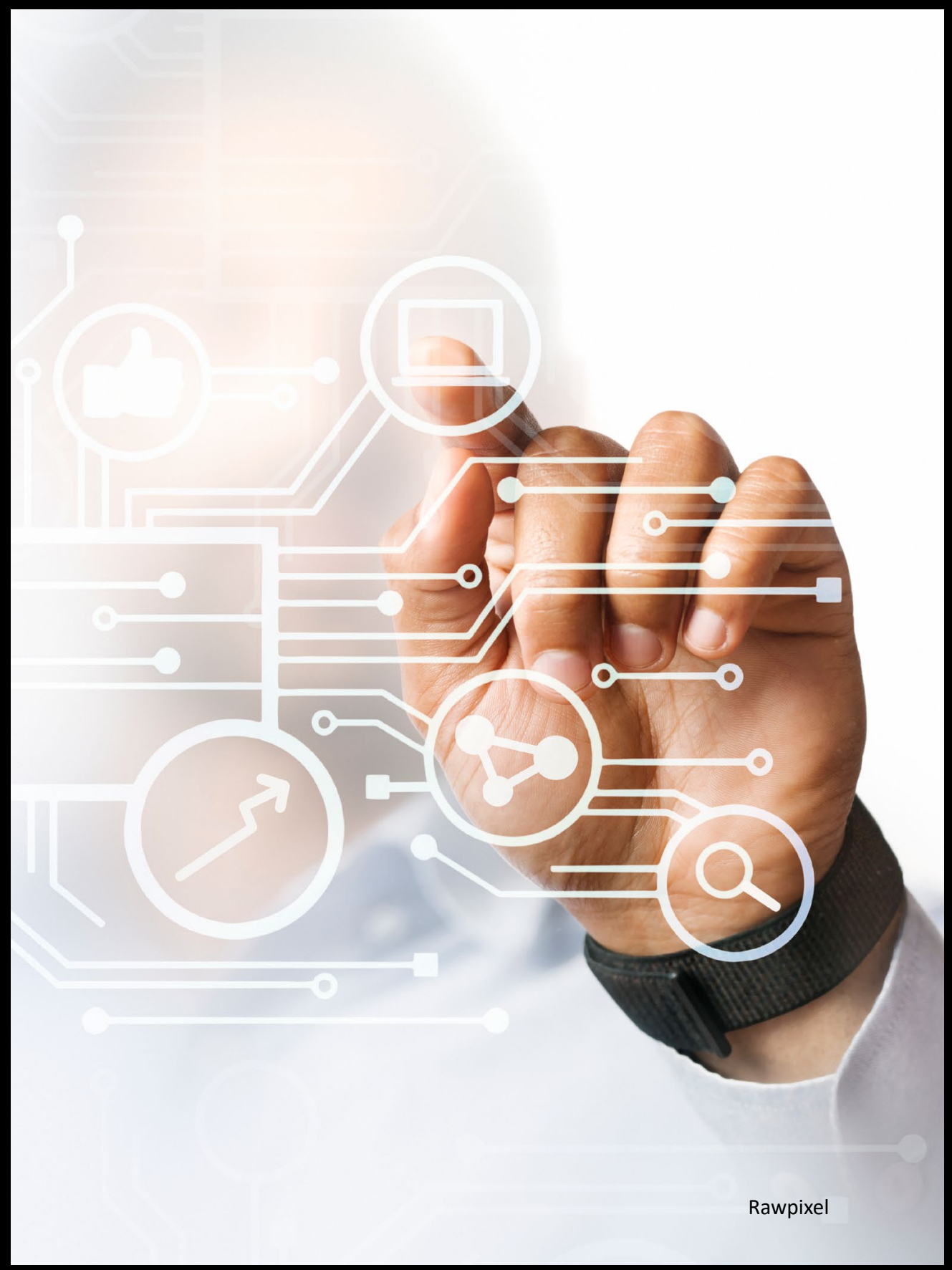




\section{Yapay Zekânın Medya ve Yayıncılık Alanına Etkisi}

\section{Burcu KAYA ERDEM*}

Insanlar ve makineler arasındaki iletişimin bugün ulaştğı nokta, insanlar yerine düşünebilen ve birçok alanda farklı uygulamaları yerine getiren ya da getirmesi muhtemel olan yapay zekâyı işaret etmektedir. Mikro düzeyden makro düzeye dünya yaşamını toplumsal kırılma noktaları oluşturacak biçimde etkileyen yüksek teknolojilere içkin olarak yapay zekâ, günümüzde "süper akıllı toplum" olarak deklare edilen Toplum 5.0’ın da önemli bileşenlerinden biridir. İnsanlık tarihinde görülen tüm teknolojik gelişmelerde olduğu gibi, yapay öğrenme/ makine öğrenmesinin hayat verdiği yapay zekâ da ekonomik, sosyolojik, kültürel, siyasi vb. gibi birçok alanda etkiler ortaya koyan ve bu etkiler doğrultusunda da birtakım araştırmaların gerçekleştirilmesine neden olan bir gelişme olarak karşımıza çıkmaktadır.

Temel olarak, insan zekâsını taklit ederek belirlenen komutları yerine getiren ve tanımlanan verileri işleyerek komutları yineleyebilen sistem veya makineler olarak tanımlanabilen yapay zekâ, birçok farklı disiplinin araştırma konularından da birini oluşturmaktadır. Zira, 17. yüzyılda pozitivist düşünceler bağlamında (Kurzweil, 1985), matematik alanının çalışma konusu olan ve insan zekâsı olmaksızın kendi kendine hesaplamalar yapabilen makine tahayyülü ve oluşturma çalışmaları, günümüzde yapay zekâ uygulamalarının çıkış noktası (Nilsson, 2019) olarak bilinmektedir. Temel matematik hesaplamalarının ötesine geçen yapay zekâ uygulamaları, bugün günlük hayatın birçok alanında kullanılabilir hâle gelmiştir ve süper akıllı makineler periferisinde süper akıllı toplumların da doğuşuna ortam hazırlamaktadır. İletişimden eğitime, bankacılıktan sağlığa ve ulaşıma kadar birçok alanda yararlanılan yapay zekâ uygulamaları, Aristo'nun otomasyon düşünün günümüz itibariyle en ileri noktasına işaret etmektedir.

* Prof. Dr., İstanbul Üniversitesi İletişim Fakültesi Gazetecilik, burcu.erdem@istanbul.edu.tr ORCID: 0000-0001-5356-0720 DOI: 10.37679/trta.1002525 
Insanlar yerine düşünebilen makineler fikrini, akademik dünyada gündeme getiren Turing'den (1950) bu yana, “Makineler düşünebilir mi?” tartş̧ması sürmekte ve eş zamanlı olarak yapay zekâyı yaşama dâhil edilen çeşitli programlar da yazılmaya devam etmektedir. Elbette, yapay zekânın farklı alanlardaki varlığının yaygınlaşması ve geniş kitlelerce kullanılması, bu tartışmalara hız kazandırmaktadır. Yapay öğrenme, insan beyninin çalışma yapısı göz önünde bulundurularak oluşturulan yapay sinir ağları ile tasarlanmıştır (Say, 2019, s. 98). Bu sebeple, söz konusu tartışmada, insan beyninin salt zekâdan ibaret olmadığı, bilinç ve çıkarımsama faktörünün (Köroğlu, 2017) de bu çalışma yapısına dâhil olduğu savları, "Makineler insanlar gibi düşünebilir mi?" sorusunu olumsuzlamakta ve beraberinde yapay zekâ öznesi problematiğini gündeme taşımaktadır. Bu tartışmaların yanı sıra yapay zekâ ile ilgili bir başka tartışma konusu da diğer tüm teknolojik gelişmelerde olduğu gibi, yapay zekânın etkin olduğu alanlardaki olumlu ve olumsuz etkileridir. Elbette, tüm teknolojik gelişmeler, ortaya çıkışları itibariyle insan yaşamını kolaylaştıracak biçimde otonom imkânlar sunmaktadır. Yapay zekâya dayalı algoritmalar, neredeyse temel ihtiyaçlarından biri hâline gelen akıllı telefonlarla birlikte, gündelik yaşantının merkezine konumlanmış durumdadır. Sağlık, banka, sosyal medya, müzik, konum, yemek, market ve alışveriş uygulamaları, bu konumlanmayı gerçekleştiren ihtiyaçlar olarak karşımıza çıkmaktadır.

Insan zekâsının yürütebileceği işleri yapabilme yeteneğinde olan yapay zekâ, farklı sektörlerdeki işleyişi de etkileme gücüne sahiptir. Dolayısıyla yapay zekâ, etkilediği sektörlerde köklü değişikliklere yol açma potansiyeli taşımaktadır. Dijitalleşme, geleneksel medya ve yayıncılık pratiklerini birçok açıdan köklü dönüşümlere uğratmışken yapay zekâ teknolojileri ise bu dönüşümlerin farklı bir boyuta taşınmasına neden olmuştur. Her teknolojik gelişme, medyanın içeriklerini iletme biçimini, hatta içeriğin bizzat kendisini etkilemiştir. Bu noktada medya sektöründe; gazetecilik, televizyon, sinema ve halkla ilişkiler gibi farklı alanlarda spesifikleşen birtakım yapay zekâ uygulamaları ile karşılaşmak mümkündür. Robot gazeteciler ya da algoritmik habercilik bu uygulamalardan biri olarak karşımıza çıkmaktadır. Google'ın finanse ettiği "The Digital News Initiative” örneğinde de olduğu gibi, robot gazeteciler uygulamasında, normal bir robotta kullanılan yapay zekâdan farklı olarak, sanal ortamdan haber olabilecek güncel ve doğru veriyi filtreleyip bunu haber yapabilme özelliği barındıran yapay zekâ aynı zamanda bu işlemi herhangi bir komuta gerek duymadan devamlı yapabilmektedir (Akgül ve Ayer, 2018, s. 2321). Elbette bu gazetecilik biçimi, yapay zekâ teknolojileri ile büyük veri birlikteliğini taşır niteliktedir; verileri toplayan, filtreleyen ve haber üretimini otomatik olarak sağlayan yapay zekâ, habercilik alanında insandan bağımsız bir işleyişi de gündeme taşımaktadır. 
"Yapay zekâ haberciliği, yapay zekânın, algoritmayı geliştiren programcı(lar) hariç, insanlardan herhangi bir girdi olmadan otomatik olarak haber yazması için kullanılması sürecidir. Algoritmik habercilikte, üretilen metinler genellikle insan yazarlar tarafindan yazılan bir metinden ayırt edilemez ve üretilen metin belgelerinin sayısı el ile üretilebilen editoryal imkânlardan çok daha fazla bir sayıda ve kısa zamanda gerçekleşmektedir. Bu habercilik biçiminde amaç, zamandan ve insan emeğinden olabildiğince bağımsız hareket etmektir" (Bulut, 2020, s. 299).

Sibernetik muhabir olarak tanımladığı "Lynx Insights" isimli otomasyon aracı ile yapay zekâ destekli gazetecilik uygulamalarından yararlanan Reuters, bu araçla, bir muhabirin edinebileceği veriyi daha yüksek hızda ve boyutta elde edebilmektedir. Haber üretimi ya da habere konu olan verilerin elde edilmesi ve kullanılması noktasında editoryal sürece büyük katkılar sağlayacağı düşünülen araç, robot gazeteciliğin örneklerinden biri olarak karşımıza çıkmaktadır.

Yapay zekâ teknolojilerinden faydalanılarak gerçekleştirilen gazetecilik/ habercilik pratikleri, geleneksel olandaki zaman ve mekân gibi eşzamanlılık durumunu ve ekonomik kaynak gibi intiyaçları ortadan kaldırabilme ya da en aza indirebilme olanağı sağlamaktadır. Bunun yanı sıra editoryal ve yayın sürecine ilişkin gereksinimler de azalmakta ve farklılaşmaktadır. Sonuç olarak yapay zekâ teknolojileri hem medya sektöründeki kolektif işleyişi hem de yapım ve yayın sürecinin her noktasında duyulan insan emeği ihtiyacını azaltarak yoluna devam etmektedir.

Tıpkı robot gazeteciler gibi, robot kameramanlar, robot oyuncular, robot senaryo yazarları ve robot kurgucular da medya sektöründe yapay zekânın üstünlüğünün önünü açan gelişmelerdir. Senaryosu yapay zekâ tarafindan yazılan ve prömiyeri 2016 yılında yapılan Sunspring isimli kısa film bu gelişmelerin örneklerinden biridir (The Guardian, 2016). Yapay zekânın, 1980 ve 1990'lı yıllarda çekilen bilim kurgu filmlerinin senaryolarını analiz ederek yazdığı filmin senaryosunu, her ne kadar geleneksel senaryo metotlarına uymasa ve anlam akışı açısından tutarsız olarak yorumlansa da gelecekte tüm bileşenleri ile yapay zekânın üretebileceği filmlere yönelik ışık tutan bir örnek olarak nitelendirmek mümkündür. Yine 2016 yııında çekilen Morgan filminin fragmanı, yapay zekâ teknolojisi tarafindan oluşturulmuş ve izleyicilerle paylaşılmıştır (Cevher, Aydın, 2020). Morgan filmi, aynı zamanda sinemanın kurgu aşamasında ilk yapay zekâlı kullanım örneğini içermektedir (Zengin, 2020, s. 167). Önümüzdeki yıllarda tamamlanması planlanan b isimli bilim kurgu filminde ise Japon bilim insanları tarafindan geliştirilen "Erica" adında bir robot oyuncunun -sinema tarihinin ilk robot oyuncusu olarak- yer alacağı aktarılmıştır (Keegan, 2020). 
Algoritma destekli teknolojiler aynı zamanda, sinema gösteriminde izleyiciler için kişiselleştirilmiş imkânlar sunmaktadır.

"Yapay zekâ çağında filmlerin gösterim alanı olarak internet tabanlı web sitelerinin ön
planda olduğu görülmektedir. Video On Demand (VOD) olarak bilinen isteğe bağı bu
video izleme platformlarında ise yapay zekâ algoritmalarının kullanılmaya başlandığı
görülmektedir. İnternete dayalı bu medya dağıtım sistemiyle sinema filmleri, belgesel-
ler, televizyon dizileri ve programları gibi çeşitli içerikler kullanıcılara ulaştırılmaktadır" (Zengin, 2020, s. 169).

Geleneksel seyir deneyimlerini kökten etkileyen dizi ve film yayıncılığında kişiselleştirilmiş gösterimler, Netflix platformu ile öne çıkarken son yıllarda hem küresel hem de yerli dijital platformların sayısı ve bu platformlara yönelik talep de giderek artmaktadır. Dijital hikâye anlatıcılığı ve sinemada yapay zekâ konusunu irdeleyen Anadolu'ya (2019, s. 46) göre “Anlat biçimleriyle birlikte izleyicinin dönüşmesi gibi veri tabanları ile şekillendirilen yapay zekâ da endüstride tavsiye edici, karar alıcı ve bunu uygulayıcı bir yapıya bürünmektedir. Şu an için yapay zekâ, izleyici alışkanlıklarını ve beklentilerini ölçerek senaryo konusunda müdahalelerde bulunmak aşamasına girmiştir." Bu durum, yapay zekâ teknolojisinin ileriye giden izleği boyunca anlatılar üzerinde hâkimiyet kurabileceği, içeriklerin baskın yaratıcısı olarak karşımıza çıkabileceği bir zamana uzak olmadığımızın altını çizmektedir.

Halkla ilişkiler ve reklamcılık alanı da yapay zekâ teknolojilerinden büyük oranda faydalanan bir sektör durumundadır. Planlama, organizasyon, hedef kitleyi tanıma, etkileşimi gözlemleyebilme (Sarıŏlu, 2019, s. 135) ve davranışı öngörebilme ve büyük veriler ışığında kampanyalar, tanıtım veya reklam fikirleri üretebilmek açısından yapay zekâ algoritmaları, sektöre büyük kolaylıklar sağlamakta, insan olmanın doğasından kaynaklı veya maddi kaynak dolayısıyla ortaya çıkan birtakım zorlukları ortadan kaldırma imkânına sahip olmaktadır. Özellikle tüketicilerin satın alma davranışlarının analizi büyük veri ve yapay zekâ algoritmaları aracılığı ile gerçekleştirilebilmekte bu da sektörün genişlemesine ve marka faaliyetlerinin etkinleşmesine neden olmaktadır.

\footnotetext{
“Kampanyaları oluşturmak kullanılabilir bilgiler bulmak için haftalar alan insan gücüne ihtiyaç duyulur. Yapay zekâ, bu verileri çok çabuk bir biçimde derler, toplar ve kullanılacak hâle dönüştürür. Yapay zekâ, hazırlanan kampanyaların tanıtım e-postaları ve sosyal medya gönderilerini göndermek için doğru zamanları ve doğru yerleri de belirler. Yapay zekâ sayesinde halkla ilişkiler profesyonelleri, bir kampanyanın en etkili olacağı konuyu, zaman ve sosyal kanalların analizini yüksek doğru oranlı tahminlerle yapabilirler" (Aydınalp, 2020, s. 2292).
} 
Bu bağlamda yapay zekâ algoritmaları, halkla ilişkiler alanında medya planlaması açısından önem arz etmektedir. Geleneksel halkla ilişkiler uygulamaları ve reklamcılık faaliyetlerini etkileyen ve dönüşüme uğratan bu etkiler, sektördeki önde gelen markaların günümüzdeki başarılarının arkasındaki bileşenlerden biri olarak görülmektedir.

Medya ve yayıncılık sektörünün yapay zekâ teknolojileri bağlamında yeniden yapılanması, teknolojik determinist perspektifle yukarıda aktarabildiğimiz birtakım yenilikler, olumlu etkiler ve değişikliklerle yorumlanabilirken medyayı eleştirel yaklaşımla ele alan teorisyenler ve araştırmacılara göre söz konusu yeniliklerin toplum üzerindeki olumsuz etkilerine de odaklanmak gerekmektedir.

Güz ve Yeğen (2018), robot gazetecilik konulu çalışmalarında, ulusal ve yerel medya çalışanları ile görüşmeler yapmış ve bu yeni gazetecilik türü konusundaki görüşlerini almıştır. Buna göre, araştırmaya katılan medya mensuplarının robot gazetecilik konusunda tedirgin ve kısmen tepkili olduğu bulgusuna ulaşmışlardır. Ek olarak, bir robot gazetecinin duyguları, hassasiyetleri, değerleri olan geleneksel bir gazeteci ile kıyaslanmasının ve onun yerini tam olarak alabilmesinin mümkün görülmediğinin altını çizmişlerdir (sf. 337). Gazeteciliğin, topluma içkin sorumlulukları göz önünde bulundurulduğunda toplumu anlayabildiği ve analiz edebildiği ölçüde başarılı olabileceğini ve topluma fayda sağlayacağını söylemek yanlış olmayacaktır. Dolayısıyla, otonom bir gazetecilik anlayışı bu nokta hem medya profesyonelleri açısından hem de toplum açısından olumsuz etkilere yol açma potansiyeli taşımaktadır.

Zengin (2020, s. 173) ise film endüstrisinde yapay zekâ kullanımının neden olduğu tartışma ve sorunları; işsizlik, yaratıcı yazarlığın ve özgünlüğün yitirilmesi, sinema dili ve estetiğinin değişmesi, telif hakları ve sorumluluklar, yanıltıcı veriler, kişiselleştirilmiş sinemanın olumsuz etkileri, ön yargı ve veri sahibinin hakları konu başlıkları ile özetlemiştir.

Olumsuz etkileri sektörel olarak spesifikleştirmenin ötesine geçtiğimizde, yapay zekâ teknolojilerinin kullanan ya da kullanmaya hazırlanan yayıncıların ve medya profesyonellerinin, dijital dünyanın günümüzdeki en temel gerekliliklerinden biri olan etiği göz önünde bulundurmasını gerektirmektedir. "Algoritmalar nedeniyle, kullanıcıların kişisel verilerinin ne kadar güvende olduğu tartışmalı bir konu hâline gelmiştir çünkü algoritmaya dayalı yapay zekâ uygulamaları, verileri toplarken ve işlerken bir taraftan da bu verilerin gizliliğini ihlal edebilmektedir. Algoritmaya dayalı pek çok uygulama, kullanıcıların dijital ortamdaki izlerini takip edebilmektedir. Bunun da ötesinde kullanıcıların kişisel verileri, reklam verenler ile onların izinleri olmaksızın paylaşılarak kullanıcılar birer metaya dönüştürülebilmektedir" (Kayıhan, v.d., 2021). Dijital kapitalist sürecin bileşenlerinden biri olarak karşımıza çıkan göze- 
tim, bu bağlamda kişisel veriler üzerindeki etik ihlallerle doğrudan doğruya ilişkilidir. Medya tüketicilerinin hangi verilerinin nasıl ve ne için işlendiği ve kullanıldığının ya da tamamıyla bu pratiklerin gerçekleştirildiğinin ve/ veya gerçekleştirilmediğinin şeffaflıkla paylaşılması, izleyicinin, okuyucunun veya dinleyicinin medya ve yayıncılık alanına olan güveni açısından önemlidir.

Yapay zekâ, medya ve yayıncılık alanında bilgiye ilişkin güvenlik sorunsalını da beraberinde getirmektedir. Yapay zekâ teknolojileri ve yapay öğrenmedeki gelişmeler, sahte içeriğin oluşturulmasında ve bu içeriklerin kullanıcılara ulaşması yönünde dikkat çekici bir artş̧a neden olmuştur (Agarwal v.d., 2019, s. 38). Sahte haber ve daha genel ifadeyle sahte yayıncılığa yol açan manipülatif içerikler, yapay zekâ teknolojisine içkin derin öğrenme teknikleri ile üretilebilmektedir. Özellikle son yıllarda karşılaşılan ve dünya liderlerinin derin öğrenme yoluyla üretilmiş görüntüleri, gerçeğinden ayırt edilmesi güç deepfake (derin sahte) videolarla kullanıcılara sunulmaktadır. Dolayısıyla yapay zekâ teknolojileri, medya manipülasyonunun çağımızdaki yaratıcısı olarak karşımıza çıkabilmektedir. Bu durum, medya ve yayıncılık alanında neyin gerçek neyin sahte olduğunun ayırt edilemediği, gerçeklik algısının deforme edildiği, Baudrillard’ın (2014) hiper gerçek evreninin uzantısı olan bir konjonktüre işaret etmektedir. Yapay zekâ destekli medyanın kamuoyu üzerindeki etkisi, üretilen dezenformatif içeriklerle yanlış yönlendirme, toplumsal kutuplaşma ve ayrımcılık pratiklerinin oluşumuna kadar uzanan bir dizi sorunsalı beraberinde getirme potansiyeline sahiptir. Elbette yapay zekâ teknolojileri dezenformatif içeriklerin yaratıcısı olduğu gibi bu içeriklerin doğrulanması ve önlenmesi noktasında çözüm üretecek biçimde de kullanılabilme potansiyeli taşımaktadır. Bu sebeple bu alanda yapılacak çalışmalara ağırık verilmesi, yanlış bilginin hızla doğrulanması açısından önemlidir.

Karşı konulamaz bir hızla ilerleyen yüksek teknolojiler, kullanılmaya başlandığı her alanda olduğu gibi medya ve yayıncılık alanında da yapısı ve işleyişine uygun gereksinimleri beraberinde getirmektedir. Bu sebeple sadece medya ve yayıncılık üretimlerinin, işleyişinin ve ürünlerin içerik yapılarının değişimi değil, bu alanda çalışacak profesyonellerin eğitimi de teknolojilere uygun biçimde vurgulanmalıdır. Yapay zekâ uygulamalarını oluşturan algoritmaları okuyabilmek hem bu teknolojileri üretmek hem de bu teknolojilerin etkilerinin farkındalığı ile bilinçli medya tüketicileri olabilmek adına önem arz etmektedir. Kullanıcıların yapay zekâ teknolojilerini kullanma motivasyonları, bu teknolojilerle üretilen uygulamalara yönelik algı, tutum ve davranış analizleri, okuryazarlık durumları, yine söz konusu uygulamaların medya ve yayıncılık sektörüne etkilerine ilişkin saha araştırmaları ve durum analizleri, yapay zekânın etkilerini ölçebilmek ve olumlu ya da olumsuz etkileri konusunda hazırlıklı olmak ve sektörde ilerleyebilmek adına gerekli görülmektedir. 


\section{Kaynakça}

Agarwal, S., Farid, H., Gu, Y., Mingming, H. Nagano, K., Li, H. (2019). Protecting world leaders against deep fakes. Proceedings of the IEEE/CVF Conference on Computer Vision and Pattern Recognition (CVPR) Workshops. pp. 38-45.

Akgül, B., Ayer, Z. (2018). Sanayi 4.0 sürecinde medyada sektörel dönüşüm. Opus Uluslararası Toplum Araştırmaları Dergisi, 9 (16), 2312- 2327.

Anadolu, B. (2019). Dijital hikâye anlatıcılığı bağlamında yapay zekânın sinemaya etkisi: Sunspring ve It's No Game filmlerinin analizi. Erciyes Illetişim Dergisi, Özel Sayı 1, 39- 56.

Aydınalp Ilıcak, G. S. (2020). Halkla ilişkiler perspektifiyle yapay zekâ, Turkish Studies- Social, 15 (4), 2283- 2300.

Baudrillard, J. (2014). Simülakrlar ve Simülasyon. O. Adanır (Çev.). Ankara: Doğu Batt.

Bulut, S. (2020). Dijital çağda medya: makine öğrenmesi, algoritmik habercilik ve gazetecilikte işlevsiz insan sorunsalı, Selçuk Iletişim, 13 (1), 294- 313.

Cevher E, Aydın Y. (2020). Yapay zekânın şafağında sinema: Morgan filmi fragmanı örneği. Gümüşhane Üniversitesi Illetişim Fakültesi Elektronik Dergisi, 8(1), 614 - 642.

Güz, N., Yeğen, C. (2018). Bir gazetecilik biçimi: Robot gazetecilik. Uluslararası Dijital Çağda Iletişim Sempozyumu, 18- 19 Ekim 2018, Mersin.

Kayıhan, B., Narin B., Fırat, D., Fırat, F. (2021). Algoritmalar, yapay zekâ ve makine öğrenimi ekseninde gazetecilik etiği: Uluslararası akademik dergilere yönelik bir inceleme, TRT Akademi, 6 (12), 296- 326.

Keegan R. (2020). A.I. Robot Cast in Lead Role of \$70M Sci-Fi Film. https://www.hollywoodreporter.com/news/general-news/ai-robot-cast-lead-role-70m-sci-fifilm-1300068/

Kurzweil R. (1985). What is artificial intellingence anyway?. American Scientist, 73, 258- 264. Köroğlu Y. (2017). Yapay zekânın teorik ve pratik sınırları, VI. Evrim, Bilim ve Eğitim Sempozyumu'nda sunulan bildiri, Boğaziçi Üniversitesi, İstanbul.

Nilsson J. N. (2019). Yapay zekâ geçmişi ve geleceği. İstanbul: Boğaziçi Üniversitesi Yayınevi. Say C. (2019). 50 soruda yapay zekâ, İstanbul: Bilim ve Gelecek Kitaplığı.

Sarıoğlu, E. B. (2019). Dijital halkla ilişkiler. Konya: Eğitim Yayınevi.

The Guardian. (2016). This is what happens when an Al-written screenplay is made into a film. https://www.theguardian.com/technology/2016/jun/10/artificial-intelligence-screenplay-sunspring-silicon-valley-thomas-middleditch-ai

Turing M. A. (1950). Compuing machinery and intelligence. Mind, 236, 433- 460.

Zengin, F. (2020). Akıllı makine çağı sinemasına giriş: Sinema sanatında yapay zekâ teknolojilerinin kullanımı. İletişim Çalışmaları Dergisi, 6 (2), 151- 177. 